\title{
ANP MODEL FOR ASSESSING SOCIO-ENVIRONMENTAL VULNERABILITY OF A RARAMURI COMMUNITY IN MEXICO
}

*Note: Do not include the author(s) names and information as this document will be blind reviewed and they will be entered during proposal submission.

\section{ABSTRACT}

We present here the ANP model developed in a response to a federal court requesting an assessment of the socio-ecological impacts caused by the construction of an airport on a Raramurí indigenous community in Mexico. The most challenging issue in ascertaining these impacts was the consideration of cultural and spiritual aspects of the community's way of living. Accordingly, the ANP model was based upon the notion of 'sustainable livelihoods' of rural communities. Results provided accurate estimates of monetary costs of foreseeable compensation actions to be considered in the ensuing settlement negotiations.

Keywords: vulnerability, livelihoods, analytic network process, socio-ecological impacts.

\section{Introduction}

We present here the ANP model used to ascertain the socio-environmental impacts caused by the construction of an airport on the community Bosques San Elías-Repechique of the Raramurí Nation (referred as the community hereafter), in the Sierra Madre Occidental, state of Chihuahua, Mexico. For the Raramurí, the basic unit of social organization is the family household, which is part of a system of homesteads dispersed over the landscape. The community sued the state government for the construction of the airport in a federal court in 2014. The sentence of the federal court ordered the state to indemnify the community for any loss arising from the construction of the airport, so that the community could continue its way of living, in accordance with its own culture and spirituality. In 2015, the court called upon us as expert witness to prepare a report to be used by the community in the settlement negotiations with the state government.

\section{Literature Review}

Livelihood analysis conceptualizes household capacities in terms of five categories of assets, or capitals: human, social/political, financial, natural and physical (Scoones 1998). It emphasizes how people access to assets, the combination and transformation of assets to meet material and experiential needs, and the cultural attributes that enable the 
ISAHP Article: A Style Guide for Paper Proposals To Be Submitted to the International Symposium on the Analytic Hierarchy Process 2016, London, U.K.

enhancement of the asset base (Bebbington 1999). The AHP/ANP has been applied in previous research on livelihoods (Eakin and Bojórquez-Tapia 2008, Eakin et al. 2011).

\section{Objectives}

The objectives of the decision model presented here were to ascertain the vulnerability of the community caused by the socio-ecological impacts to related to the construction of the airport, and to propose monetary estimates for alternative compensation measures.

\section{Methodology}

The model was based on data that resulted from combining secondary sources, expert knowledge, surveys and interviews to members of the community. The livelihood assets were synthesized as an ANP model in which the clusters corresponded to the five livelihood category assets, and the elements within each cluster corresponded to the specific assets identified in our study.

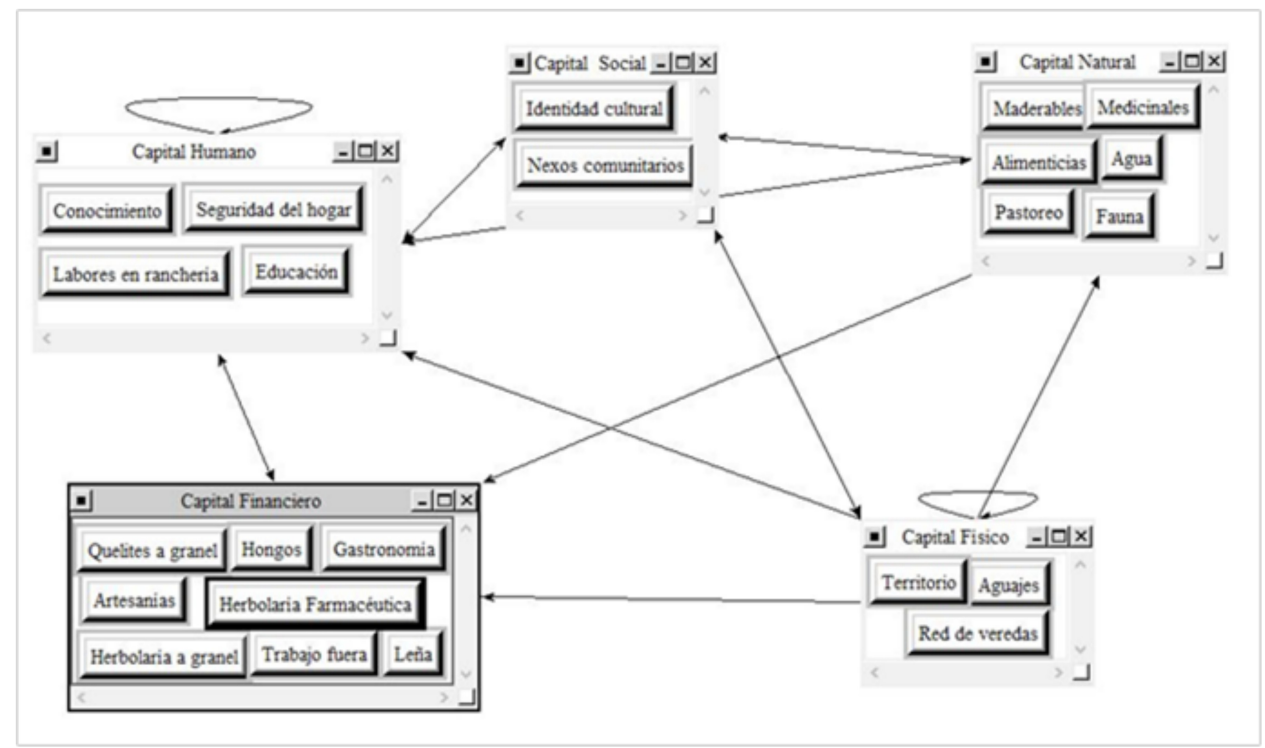

\section{Conclusions}

The ANP proved to be effective to address the challenging issue of technically ascertaining the facts regarding socio-environmental impacts related to culture and spirituality, while providing accurate estimates of monetary costs of foreseeable compensation actions.

\section{Key References}

Bebbington, Anthony. 1999. "Capitals and Capabilities, A Framework for Analyzing and Rural Livelihoods." World Development 27 (12): 2021-44. doi:10.1016/S0305750X(99)00104-7.

Eakin, Hallie, and Luis A. Bojórquez-Tapia. 2008. "Insights into the Composition of Household Vulnerability from Multicriteria Decision Analysis." Global Environmental 
ISAHP Article: A Style Guide for Paper Proposals To Be Submitted to the International Symposium on the Analytic Hierarchy Process 2016, London, U.K.

Change 18 (1): 112-27. doi:10.1016/j.gloenvcha.2007.09.001.

Eakin, Hallie, Luis A. Bojórquez-Tapia, Rafael Monterde Diaz, Edwin Castellanos, and Jeremy Haggar. 2011. "Adaptive Capacity and Social-Environmental Change: Theoretical and Operational Modeling of Smallholder Coffee Systems Response in Mesoamerican Pacific Rim.” Environmental Management 47 (3): 352-67. doi:10.1007/s00267-0109603-2.

Scoones, Ian. 1998. "Sustainable Rural Livelihoods a Framework for Analysis." IDS Working Paper 72 72: 1-22. doi:10.1057/palgrave.development.1110037. 